\title{
Adherence to Cancer Prevention Guidelines among Older White and Black Adults in the Health ABC Study
}

\author{
Audrey Y. Jung ${ }^{1}$, Iva Miljkovic ${ }^{2}$, Susan Rubin ${ }^{3}$, Stephen B. Kritchevsky ${ }^{4}$, Heidi D. Klepin ${ }^{5} @$, \\ Anne B. Newman ${ }^{2}$, Jane Cauley ${ }^{2}$, Hilsa Ayonayon ${ }^{3}$, Tamara B. Harris ${ }^{6}$ and Rachel A. Murphy ${ }^{1, *}$ \\ 1 School of Population and Public Health, University of British Columbia, Vancouver, BC V6T 1Z3, Canada; \\ audrey.y.jung@gmail.com \\ 2 Center for Aging and Population Health, Department of Epidemiology, University of Pittsburgh, \\ Pittsburgh, PA 15261, USA; MiljkovicI@edc.pitt.edu (I.M.); NewmanA@edc.pitt.edu (A.B.N.); \\ JCauley@edc.pitt.edu (J.C.) \\ 3 Department of Epidemiology and Biostatistics, University of California at San Francisco, \\ San Francisco, CA 94158, USA; SRubin@psg.ucsf.edu (S.R.); HAyonayon@psg.ucsf.edu (H.A.) \\ 4 Sticht Center for Healthy Aging and Alzheimer's Prevention, Wake Forest School of Medicine, \\ Winston-Salem, NC 27157, USA; skritche@wakehealth.edu \\ 5 Comprehensive Cancer Center, Wake Forest School of Medicine, Winston-Salem, NC 27157, USA; \\ hklepin@wakehealth.edu \\ 6 Laboratory of Epidemiology and Population Sciences, National Institute on Aging, \\ Bethesda, MD 20814, USA; harris99@nia.nih.gov \\ * Correspondence: rachel.murphy@ubc.ca; Tel.: +1-604-822-1397
}

Received: 9 April 2019; Accepted: 30 April 2019; Published: 3 May 2019 updates

\begin{abstract}
One-third of cancers can be prevented through healthy lifestyles. This study investigates the prevalence of and factors associated with engagement in cancer prevention guidelines in a population-based cohort of 2124 older white and black men and women. We used Health ABC data to construct a score from 0 (lowest adherence) to 7 (greatest adherence) based on the sum of seven recommendations for cancer prevention from the World Cancer Research Fund/American Institute for Cancer Research; body fatness (maintenance of healthy body weight), physical activity (at least moderately physically active), diet (fruit, vegetables, fiber, and red and processed meat), and alcohol. Mean (SD) scores in men and women were 3.24 (1.09) and 3.17 (1.10). Lower scores were associated with younger age (women only), black race, current smoking, and prevalent cardiovascular disease. Less than $1 \%$ of men and women adhered to all recommendations. Of the individual guidelines, adherence was lowest for fiber ( $9 \%$ of men; $6 \%$ of women) followed by physical activity ( $26 \%$ of men; $18 \%$ of women), and body weight ( $21 \%$ of men; $26 \%$ of women). These results suggest a critical public health need, especially given the growing older population. Black older adults, smokers, and those with prevalent disease may be at higher risk and thus warrant additional focus.
\end{abstract}

Keywords: lifestyle; nutrition; prevention; aging

\section{Introduction}

Cancer is a global problem and the burden of cancer is growing. In 2012, there were 14.1 million new cancer cases [1], which is projected to reach 22.2 million by 2030 [2]. The increase in cancer incidence is a reflection of population growth, the aging population and change in the prevalence and distribution of risk factors. The growing prevalence of obesity, a risk factor for numerous cancers, will have a major impact on cancer incidence in the coming decades [3]. Cancer prevention has thus been identified as a critical component of cancer control to mitigate the burden of cancer [4]. 
Lifestyle is a key component of cancer prevention strategies: one-third of cancers can be prevented by maintaining a healthy body weight, eating a healthy diet, and being physically active $[5,6]$. The World Cancer Research Fund (WCRF) and the American Institute for Cancer Research (AICR) provide evidence-based guidelines that focus on lifestyle recommendations to achieve and maintain a healthy body weight throughout life, adopt a physically active lifestyle, consume a healthy diet with an emphasis on plant foods, and limit alcohol consumption [7]. The recommendations include population goals and personal recommendations that have been used to inform policies and programs to reduce the incidence of cancer.

Despite the importance of lifestyle factors in cancer prevention, engagement in healthy lifestyle behaviors is low. A number of studies have examined the extent of adherence to preventive guidelines for cancer [8-16] in population-based cohorts of adults from different countries and consistently report low adherence to guidelines. However, there is limited information in older adults, despite more than half of all cancers occurring in people aged 65 and older [17].

The limited information may stem from the prevalent bias that older populations all suffer from chronic disease, and thus focus is directed towards disease management and not prevention of diseases [18] or that older adults are often excluded from randomized controlled trials of behavior change [19]. The time course of development for many cancers often exceeds a decade, suggesting that avoidance of risk accumulation must occur far before the onset of cancer [20]. Nevertheless, lifestyle behaviors are generally consistent over time and a greater understanding of cancer prevention is critically needed in older adults given the growing older population, and life expectancy that exceeds 10 years for many adults over age 65. Data from the Women's Health Initiative suggests that this age range may be an etiologically relevant time period for cancer prevention. Women in the study who were aged 50-79 and had intentional weight loss, which tended to bring body weight in line with recommendations for a healthy body weight, had a lower risk of endometrial cancer [21]. Furthermore, a meta-analysis of seven cohorts, ranging in mean age from 60-70, showed that greater adherence to cancer prevention recommendations was associated with reduced cancer risk [16], thus suggesting older populations are not past a critical window for cancer prevention.

The aim of this study was to provide observational data on the prevalence of engagement in guidelines for primary cancer prevention in a population-based cohort of older white and black men and women. Factors associated with adherence were also explored to provide insight into populations that may benefit from targeted cancer prevention strategies.

\section{Research Design and Methods}

\subsection{Study Population}

Data for this study are from the Health, Aging, and Body Composition (Health ABC) Study, a prospective longitudinal cohort of 3075 community-dwelling participants aged 70-79 established in 1997-1998 [22]. Participants were recruited from a random sample of white Medicare-eligible residents and all black Medicare-eligible residents in the Pittsburgh, PA, and Memphis, TN, areas. Eligibility criteria included no difficulty walking one-quarter mile, climbing 10 steps without resting, or performing mobility-related activities of daily living, free of life-threatening illness, and no enrollment in lifestyle intervention trials. All participants provided written informed consent. Protocols were approved by the institutional review board at each study site.

Body weight and physical activity were assessed at multiple time points throughout the Health ABC Study. However, the food frequency questionnaire (FFQ) was only administered at the 12-month follow-up clinic visit (year 2). As dietary intake is a key component of cancer prevention guidelines, year 2 was selected as the analytical baseline, which also coincides with body weight and physical activity assessments. Participants with cancer diagnosed prior to the analytical baseline $(n=649)$ were excluded due to the potential influence of a cancer diagnosis on health behaviors and our study focus on adherence to recommendations for primary cancer prevention. Participants who developed 
nonmelanoma skin cancer prior to the analytical baseline were included as this form of cancer tends to behave very differently from other cancers (rarely metastasizes, high cure rate) and is treated differently. Participants who did not have any data on FFQ $(n=207)$ or BMI were also excluded $(n=95)$. Therefore, a total of 2124 persons were included.

\subsection{Dietary Assessment}

To estimate usual dietary intake, participants completed a 108-item interviewer-administered modified version of the Block FFQ (Block Dietary Data Systems, Berkeley, CA, USA) based on usual eating habits over the prior 12 months [23]. The FFQ food list was developed specifically for the Health ABC Study on the basis of 24-hour recall data from the National Health and Nutrition Examination Survey III for older black and white adults living in the Northeast or Southern US. Trained interviewers used wood blocks, food models, standard kitchen measures, and flash cards to help participants estimate predefined portion size categories for each food. Interviews were periodically monitored throughout the study to ensure the quality and consistency of the data collection procedures. Intakes of select food groups were calculated by Block Dietary Data Systems. Fiber was calculated as the sum of fiber from beans, grains and fruits and vegetables and questions included specifying white versus whole wheat breads and fiber or bran cereals. Red and processed meat included bacon, sausage, hamburgers, meat load, beef, pork, hot dogs, mixed meat dishes, and lunch meats. Alcohol consumption was estimated as the number of drinks per day from beer, wine and liquor. One standard drink was defined as beverages containing $0.6 \mathrm{oz}$ or $14 \mathrm{~g}$ of pure alcohol e.g., 12 -oz of beer $(280 \mathrm{~g}), 5$-oz of wine (117 g), or a 1.5-oz shot of liquor (35 g). A small amount of missing data from the FFQ's ( $n=11,0.5 \%$ of participants for fruit and vegetables to $n=40,1.8 \%$ for red meat) was imputed with the median intake of participants of the same gender, race and study site.

\subsection{Body Weight}

Weight was measured at the analytical baseline using a calibrated scale. Height was measured using a stadiometer. Body mass index (BMI) was calculated in $\mathrm{kg} / \mathrm{m}^{2}$. At the year 1 visit participants were asked to recall their usual weight at ages 25 and 50 years [24]. Studies in Health ABC suggest that these recalled weights are valid as they have been associated with weight-related outcomes such as mobility disability [24] and mortality [25] in comparable magnitude and direction as previous studies. Recalled height at age 25 years and measured height at Health $\mathrm{ABC}$ baseline were also highly correlated $(r=0.93$, mean difference $=3 \mathrm{~cm})$ as were self-reported weight and measured weight at the year 1 visit $(r=0.98)$.

\subsection{Physical Activity}

Physical activity was assessed using a self-reported questionnaire completed at the analytical baseline that was developed specifically for the Health $\mathrm{ABC}$ Study. The questionnaire was modeled after the validated Minnesota Leisure Time physical activity questionnaire [26]. Participants reported the type, intensity and amount of physical activity in the prior 7 days. The amount of moderate and vigorous physical activity was summed and considers physical activity and exercise in the context of this older population. For example, walking for exercise, other types of walking, and heavy chores that may be considered as light or lifestyle activity in a younger population are totaled with high intensity exercise (e.g., bicycling, swimming, jogging, or rowing) in the determination of moderate and vigorous physical activity.

\subsection{Adherence Score}

Data collected in Health ABC pre-date the publication of the most recent WCRF/AICR guidelines (2018). However, as the recommendations build upon prior Expert Reports (2007 and 1997) without material changes to recommendations, the 2018 guidelines were used to facilitate comparison with future studies. Only recommendations that were quantifiable using data collected in Health ABC were included. For example, recommendations to consume fast food sparingly, consume energy-dense foods 
sparingly; limit refined starchy foods; avoid salt-preserved, salted, and salty foods; and avoid moldy cereals and pulses were not quantifiable with existing dietary data. In total, seven recommendations pertaining to maintenance of a body fatness, physical activity, plant foods, animal foods, and alcohol consumption were considered: maintenance of body weight within the normal range from age 21, avoid weight gain throughout adulthood, be at least moderately physically active, consume a diet with at least $30 \mathrm{~g}$ per day of fiber, include at least five portions/servings of nonstarchy vegetables and fruit every day, and limit consumption of red and processed meat. A composite score for adherence was generated in a manner similar to prior studies [13,27]. One point was assigned when the recommendation was met and zero points when it was not met. Criteria provided in the recommendations were used as cut points when provided (e.g., at least 5 servings of a variety of nonstarchy vegetables and fruit, $<500 \mathrm{~g} /$ week of animal foods, and at least $30 \mathrm{~g}$ of fiber per day. Otherwise cut points previously defined in the literature were used. Details on the recommendations included in the study and the application of WCRF/AICR guidelines to the Health ABC population are shown in Table 1. The overall score ranged from 0 to 7 with high scores indicating greater adherence.

Table 1. WCRF/AICR personal recommendations for cancer prevention and translation to adherence score in the Health ABC Study.

\begin{tabular}{|c|c|c|c|c|}
\hline Personal Recommendations & Operationalization & Score & $\begin{array}{l}\text { Men } \\
n(\%)\end{array}$ & $\begin{array}{l}\text { Women } \\
n(\%)\end{array}$ \\
\hline \multicolumn{5}{|l|}{ Body fatness } \\
\hline \multirow{2}{*}{$\begin{array}{l}\text { Maintain body weight within the } \\
\text { normal range from age } 21^{*}\end{array}$} & All other combinations & 0 & $802(79.2)$ & $822(73.9)$ \\
\hline & $\begin{array}{l}\text { BMI } 18.5 \text { to } 24.9 \mathrm{~kg} / \mathrm{m}^{2} \text { at } 25 \mathrm{y}, \\
50 \mathrm{y} \text { and } 71-80 \mathrm{y}\end{array}$ & 1 & $210(20.8)$ & $290(26.1)$ \\
\hline \multirow{2}{*}{$\begin{array}{l}\text { Avoid weight gain throughout } \\
\text { adulthood * }\end{array}$} & $\geq 5 \%$ weight gain & 0 & $689(68.1)$ & 879 (79.1) \\
\hline & $<5 \%$ weight gain & 1 & $323(31.9)$ & $233(21.0)$ \\
\hline \multicolumn{5}{|l|}{ Physical activity * } \\
\hline \multirow[t]{2}{*}{$\begin{array}{l}\text { Be at least moderately physically } \\
\text { active and follow or exceed national } \\
\text { guidelines }\end{array}$} & $\begin{array}{l}<210 \text { minutes of moderate to } \\
\text { vigorous physical activity/wk }\end{array}$ & 0 & $747(73.8)$ & $907(81.6)$ \\
\hline & $\begin{array}{l}\geq 210 \text { minutes of moderate to } \\
\text { vigorous physical activity/wk }\end{array}$ & 1 & $265(26.2)$ & $205(18.4)$ \\
\hline \multicolumn{5}{|l|}{ Plant foods } \\
\hline \multirow{2}{*}{$\begin{array}{l}\text { Eat at least five portions/servings of a } \\
\text { variety of nonstarchy vegetables and } \\
\text { fruit every day }\end{array}$} & $\begin{array}{l}<5 \text { servings of fruits and } \\
\text { vegetables/d over last } 12 \text { months }\end{array}$ & 0 & $524(51.8)$ & $522(46.9)$ \\
\hline & $\begin{array}{l}\geq 5 \text { servings of fruits and } \\
\text { vegetables/d over last } 12 \text { months }\end{array}$ & 1 & $488(48.2)$ & $590(53.1)$ \\
\hline \multirow{2}{*}{$\begin{array}{l}\text { Consume a diet that provides at least } \\
30 \mathrm{~g} \text { per day of fiber from food } \\
\text { sources* }\end{array}$} & Dietary fiber intake $<30 \mathrm{~g} / \mathrm{d}$ & 0 & $917(90.6)$ & $1045(94.0)$ \\
\hline & Dietary fiber intake $\geq 30 \mathrm{~g} / \mathrm{d}$ & 1 & $95(9.39)$ & $67(6.03)$ \\
\hline \multicolumn{5}{|l|}{ Animal foods * } \\
\hline \multirow{2}{*}{$\begin{array}{l}\text { Limit consumption of red meat to no } \\
\text { more than } 500 \mathrm{~g} \text { a week, eat little if } \\
\text { any processed meat }\end{array}$} & $\begin{array}{l}\geq 500 \mathrm{~g} \text { red meat } / \mathrm{wk} \text { and/or } \\
\text { processed meat } \geq 50 \mathrm{~g} / \mathrm{d}\end{array}$ & 0 & $30(2.96)$ & $15(1.35)$ \\
\hline & $\begin{array}{l}<500 \mathrm{~g} \text { red meat } / \mathrm{wk} \text { and }<50 \mathrm{~g} / \mathrm{d} \\
\text { processed meat } / \mathrm{s}\end{array}$ & 1 & $982(97.0)$ & $1097(98.7)$ \\
\hline \multicolumn{5}{|l|}{ Alcoholic drinks * } \\
\hline \multirow[t]{2}{*}{$\begin{array}{l}\text { If consumed, do not exceed national } \\
\text { guidelines }\end{array}$} & $\begin{array}{l}>2 \text { drinks/d for men and } \\
>1 \text { drink/d for women }\end{array}$ & 0 & $93(9.19)$ & $65(5.8)$ \\
\hline & $\begin{array}{l}\leq 2 \text { drinks/d for men and } \\
\leq 1 \text { drink/d for women }\end{array}$ & 1 & $919(90.8)$ & $1047(94.2)$ \\
\hline
\end{tabular}

${ }^{*}$ Difference between men and women $p<0.05$ from chi-square tests. 


\subsection{Statistical Analysis}

Descriptive statistics are reported as means and standard deviations (SD) for continuous variables and as frequency and percentage for categorical variables. Linear regression models were used to determine adjusted regression coefficients and 95\% confidence intervals (CIs) between participants' composite score and potential associated factors known to be related to dietary intake and/or cancer incidence; age, race, education, smoking status, income, marital status, cardiovascular disease (coronary heart disease and stroke determined from self-report, hospitalization, and medications), and diabetes (determined from self-report, medications and clinical assessments). Logistic regression models were used to determine odds ratios (ORs) and 95\% CIs between adherence to each of the component scores separately and potential associated factors as in the linear regression models. Regression models were adjusted for age, race, and study site, except the major independent variable. All analyses were stratified by sex due to significant interactions between sex and component measures; physical activity, body weight, fruits and vegetables, fiber and red and processed meat. $p$-values were two-tailed $(\alpha=0.05)$. Analyses were performed with STATA software (version 14.1, StataCorp, College Station, TX, USA). In this cohort, the number of cancers that occurred after the analytical baseline (ascertained through ongoing cohort follow-up) is modest (295 in men and 222 in women), and were predominately prostate $(n=100)$, and lung $(n=99)$ cancers for which there is inconsistent evidence for lifestyle factors related to diet, weight and physical activity [28-30]. The next most common cancers were colon $(n=64)$ and breast $(n=57)$, which have more convincing relationships with lifestyle factors but the sample size is small. Thus, the association between adherence score and cancer incidence was not explored.

\section{Results}

Characteristics of the population are shown in Table 2. The mean age was 74.5 years (2.86 SD), $48 \%$ were men and $52 \%$ were women, and $34 \%$ of men and $44 \%$ of women were black. Most participants ( $48 \%$ of men and $40 \%$ of women) had at least a postsecondary education. Sixty percent of men and $34 \%$ of women were former smokers. Household income in men was predominately within $\$ 25,000$ to $\$ 50,000$ and $\$ 10,000$ to $\$ 25,000$ in women. Most men were married $(75 \%)$ whereas most women (46\%) were widowed. Over half of men and $44 \%$ of women reported prevalent cardiovascular disease. Prevalent diabetes was reported by $25 \%$ of men and $18 \%$ of women.

The proportion of participants who adhered to individual cancer prevention recommendations are shown in Table 1. Adherence to recommendations for red and processed meat was highest $(97 \%$ of men and $99 \%$ of women), followed by alcohol consumption ( $91 \%$ of men and $94 \%$ of women). Adherence was lowest for fiber ( $9 \%$ of men and $6 \%$ of women) followed by body weight for men $(21 \%)$ and physical activity for women (18\%). Nearly half of men and women met recommendations for fruit and vegetable consumption. Additional details on the dietary intake of foods/nutrients in the recommendations are provided in Supplementary Table S1.

The mean composite score, compiled from the individual recommendations showed low overall adherence (men: mean 3.24, SD 1.10; women: mean 3.17, SD 1.10). Frequencies of the composite score are shown in Table 3. All men and women met at least one recommendation. However, less than $1 \%$ of men and women met all seven recommendations.

The association between the composite cancer prevention score and characteristics of participants are presented in Table 4. Black men and black women's adherence to prevention recommendations were $0.28(\mathrm{SE}=0.07)$ and $0.43(\mathrm{SE}=0.07)$ points lower than white men and women. In women, older age at analytical baseline was associated with a higher score $(\beta=0.03, \mathrm{SE}=0.01)$ as was having a postsecondary education $(\beta=0.25, \mathrm{SE}=0.09)$. Women in Pittsburgh had lower scores than women in Memphis $(\beta=-0.21, \mathrm{SE}=0.06)$ as did women with household income $<\$ 10,000(\beta=-0.28, \mathrm{SE}=0.14)$. Current smokers had a composite prevention score 0.19 (men, SE 0.08) and 0.28 (women, SE 0.07) points lower than never smokers. Men and women with cardiovascular disease had a composite score that was 0.18 (SE 0.07) and 0.19 (SE 0.07) lower than those without cardiovascular disease. 
Table 2. Characteristics of participants in the Health ABC Study by sex.

\begin{tabular}{ccc}
\hline & Men $(n=1012)$ & Women $(n=1112)$ \\
\hline Age, mean (SD) & $74.7(2.85)$ & $74.4(2.87)$ \\
Black, $n(\%)$ & $342(33.8)$ & $480(43.2)$ \\
Pittsburgh site, $n(\%)$ & $506(50)$ & $577(51.9)$ \\
Education, $n(\%)$ & & \\
$<$ High school & $260(25.7)$ & $235(21.2)$ \\
High school & $264(26.1)$ & $428(38.6)$ \\
Postsecondary & $486(48.1)$ & $447(40.3)$ \\
Smoking status, $n(\%)$ & & \\
Never & $300(29.7)$ & $641(57.7)$ \\
Current & $102(10.1)$ & $97(8.73)$ \\
Former & $608(60.2)$ & $373(33.6)$ \\
<ousehold income, $n(\%)$ & & \\
\$10,000 & $63(6.90)$ & $163(17.1)$ \\
$\$ 10,000$ to $\$ 25,000$ & $313(34.3)$ & $399(41.9)$ \\
$>\$ 25,000$ to $<\$ 50,000$ & $337(36.9)$ & $277(29.1)$ \\
$\geq \$ 50,000$ & $200(21.9)$ & $114(12.0)$ \\
Marital status, $n(\%)$ & & \\
Married & $712(74.6)$ & $397(38.9)$ \\
Widowed & $129(13.5)$ & $467(45.7)$ \\
Divorced/separated & $71(7.4)$ & $105(10.3)$ \\
Never married & $42(4.40)$ & $53(5.19)$ \\
Cardiovascular disease, $n(\%)$ & $570(56.8)$ & $483(44.2)$ \\
Diabetes, $n(\%)$ & $254(25.1)$ & $204(18.4)$ \\
\hline & & \\
\hline
\end{tabular}

Table 3. Prevalence of adherence to cancer prevention guidelines by sex in the Health ABC Study, n (\%).

\begin{tabular}{ccccccccc}
\hline & $\mathbf{0}$ & $\mathbf{1}$ & $\mathbf{2}$ & $\mathbf{3}$ & $\mathbf{4}$ & $\mathbf{5}$ & $\mathbf{6}$ & $\mathbf{7}$ \\
\hline Men & 0 & $26(2.57)$ & $246(24.3)$ & $356(35.2)$ & $251(24.8)$ & $108(10.7)$ & $23(2.27)$ & $2(0.20)$ \\
Women & 0 & $19(1.71)$ & $309(27.8)$ & $421(37.9)$ & $227(20.4)$ & $100(8.99)$ & $31(2.79)$ & $5(0.45)$ \\
\hline
\end{tabular}

Table 4. Association between the composite cancer prevention score and characteristics in the Health ABC Study by sex.

\begin{tabular}{lcccc}
\hline & \multicolumn{2}{c}{ Men } & \multicolumn{2}{c}{ Women } \\
& $\beta$ (SE) & $p$-Value & $\beta$ (SE) & $p$-Value \\
\hline a Age & $0.01(0.01)$ & 0.24 & $0.03(0.01)$ & 0.004 \\
Memphis site & Reference & & Reference & \\
Pittsburgh site & $-0.05(0.07)$ & 0.47 & $-0.21(0.06)$ & 0.001 \\
White race & Reference & & Reference & \\
Black race & $-0.28(0.07)$ & $<0.001$ & $-0.43(0.07)$ & $<0.001$ \\
Education & Reference & & Reference & \\
$\quad<$ High school & $-0.12(0.10)$ & 0.24 & $0.07(0.09)$ & 0.44 \\
$\quad$ High school & $0.12(0.09)$ & 0.20 & $0.25(0.09)$ & 0.006 \\
$\quad$ Postsecondary & & & & \\
Smoking status & Reference & & Reference & \\
$\quad$ Never & $-0.13(0.13)$ & 0.30 & $0.11(0.12)$ & 0.35 \\
$\quad$ Former & $-0.19(0.08)$ & 0.02 & $-0.28(0.07)$ & $<0.001$ \\
$\quad$ Current & & & & \\
Household income & $0.02(0.17)$ & 0.90 & $-0.28(0.14)$ & 0.04 \\
$\quad<10,000$ & $-0.01(0.10)$ & 0.91 & $-0.18(0.12)$ & 0.12 \\
$\quad \$ 10,000$ to $\$ 25,000$ & $0.00(0.10)$ & 0.97 & $-0.18(0.12)$ & 0.14 \\
$\quad \$ 25,000$ to $<\$ 50,000$ & Reference & & Reference & \\
$\quad \$ 50,000$ & & & & \\
Marital status & Reference & & Reference & \\
$\quad$ Married & $-0.02(0.11)$ & 0.86 & $-0.04(0.08)$ & 0.62 \\
$\quad$ Widowed & $-0.17(0.14)$ & 0.22 & $-0.10(0.12)$ & 0.43 \\
Divorced/separated & $0.07(0.17)$ & 0.67 & $-0.06(0.16)$ & 0.71 \\
$\quad$ Never married & $-0.18(0.07)$ & 0.01 & $-0.19(0.07)$ & 0.005 \\
Cardiovascular disease & $-0.15(0.08)$ & 0.07 & $-0.15(0.08)$ & 0.08 \\
Diabetes & & & & \\
\hline
\end{tabular}

a Coefficient represents change in one year, models adjusted for age, race, and study site. Greater composite scores represent greater adherence to recommendations. 
Odds ratios (OR) for each recommendation and associated factors are shown in Table 5. Associations for red and processed meat and alcohol consumption were not considered due to the low prevalence of not meeting guidelines. The odds of adherence to the body weight recommendation was $41 \%$ lower in men with diabetes, $72 \%$ lower among black women, and $60 \%$ lower in women with diabetes. Conversely, the odds of adherence to the body weight recommendation was $55 \%$ higher among women with a postsecondary education, as well as more than 2-fold higher among those with income less than $\$ 50,000$. The odds of adherence to the weight maintenance recommendation was $31 \%$, and $25 \%$ lower in men with diabetes and cardiovascular disease. Women from the Pittsburgh site, black women, current smokers and women with diabetes had $36 \%, 53 \%, 31 \%$, and $48 \%$ lower odds of adherence to the weight maintenance recommendation, respectively. The odds of adherence to weight maintenance was more than 2-fold higher in men and women who were former smokers. The odds of meeting recommendations for physical activity were 31\% and $54 \%$ lower among black men and women, $49 \%$ lower among men who were former smokers, and $41 \%$ and $37 \%$ lower among men and women with prevalent cardiovascular disease. Men from the Pittsburgh site, older women, and women with postsecondary education had greater odds of adherence to the recommendation for fruit and vegetables. Black men, women who were former smokers, and women with cardiovascular disease had $45 \%, 44 \%$, and $31 \%$ lower odds of adherence to the recommendation for fruit and vegetables, respectively. Adherence to the recommendation for fiber was $41 \%$ lower among women from the Pittsburgh site, 38\% lower among men who were current smoker, and more than 3-fold higher among never married men.

Table 5. Associations between adherence to individual cancer prevention guidelines and characteristics in the Health ABC Study by sex.

\begin{tabular}{|c|c|c|c|c|}
\hline & \multicolumn{2}{|c|}{ Men } & \multicolumn{2}{|c|}{ Women } \\
\hline & OR $(95 \% \mathrm{CI})$ & $p$-Value & OR $(95 \% \mathrm{CI})$ & $p$-Value \\
\hline \multicolumn{5}{|l|}{ Body weight } \\
\hline Age & $1.04(0.98-1.09)$ & 0.19 & 1.04 (0.99-1.09) & 0.10 \\
\hline Memphis site & Reference & & Reference & \\
\hline Pittsburgh site & $0.95(0.70-1.28)$ & 0.72 & $0.89(0.67-1.17)$ & 0.39 \\
\hline White race & Reference & & Reference & \\
\hline Black race & $0.75(0.53-1.04)$ & 0.08 & $0.28(0.21-0.38)$ & $9.7 \times 10^{-16}$ \\
\hline \multicolumn{5}{|l|}{ Education } \\
\hline$<$ High school & Reference & & Reference & \\
\hline High school & $1.19(0.75-1.90$ & 0.46 & $1.05(0.68-1.62)$ & 0.83 \\
\hline Postsecondary & $1.48(0.97-2.27)$ & 0.07 & $1.55(1.02-2.38)$ & 0.04 \\
\hline \multicolumn{5}{|l|}{ Smoking status } \\
\hline Never & Reference & & Reference & \\
\hline Former & $1.56(0.90-2.69)$ & 0.11 & 1.59 (0.98-2.59) & 0.06 \\
\hline Current & $0.97(0.69-1.37)$ & 0.86 & $0.85(0.63-1.16)$ & 0.31 \\
\hline \multicolumn{5}{|l|}{ Household income } \\
\hline$<\$ 10,000$ & $1.01(0.49-2.09)$ & 0.99 & $2.03(1.18-3.50)$ & 0.01 \\
\hline$\$ 10,000$ to $\$ 25,000$ & $1.16(0.55-2.44)$ & 0.70 & $2.07(1.16-3.67)$ & 0.01 \\
\hline$>\$ 25,000$ to $<\$ 50,000$ & $1.11(0.51-2.43)$ & 0.79 & $2.36(1.24-4.52)$ & 0.01 \\
\hline$\geq \$ 50,000$ & Reference & & Reference & \\
\hline \multicolumn{5}{|l|}{ Marital status } \\
\hline Married & Reference & & Reference & \\
\hline Widowed & $0.84(0.52-1.36)$ & 0.48 & $0.94(0.68-1.31)$ & 0.73 \\
\hline Divorced/separated & $0.51(0.24-1.09)$ & 0.08 & $0.63(0.35-1.15)$ & 0.13 \\
\hline Never married & $0.84(0.38-1.86)$ & 0.67 & $0.98(0.51-1.86)$ & 0.94 \\
\hline Cardiovascular disease & $0.80(0.59-1.10)$ & 0.17 & $0.86(0.64-1.14)$ & 0.29 \\
\hline Diabetes & $0.59(0.40-0.87)$ & 0.01 & $0.40(0.26-0.63)$ & $<0.001$ \\
\hline
\end{tabular}


Table 5. Cont.

\begin{tabular}{|c|c|c|c|c|}
\hline & \multicolumn{2}{|c|}{ Men } & \multicolumn{2}{|c|}{ Women } \\
\hline & OR $(95 \%$ CI) & $p$-Value & OR $(95 \%$ CI $)$ & $p$-Value \\
\hline \multicolumn{5}{|l|}{ Weight maintenance } \\
\hline Age & 1.03 (0.99-1.08) & 0.18 & $1.08(1.02-1.13)$ & 0.004 \\
\hline Memphis site & Reference & & Reference & \\
\hline Pittsburgh site & $0.95(0.73-1.23)$ & 0.68 & $0.64(0.48-0.86)$ & 0.003 \\
\hline White race & Reference & & Reference & \\
\hline Black race & $1.11(0.84-1.47)$ & 0.45 & $0.47(0.35-0.65)$ & $<0.001$ \\
\hline \multicolumn{5}{|l|}{ Education } \\
\hline$<$ High school & Reference & & Reference & \\
\hline High school & $0.70(0.47-1.03)$ & 0.07 & $0.92(0.59-1.45)$ & 0.73 \\
\hline Postsecondary & $0.92(0.65-1.30)$ & 0.63 & $1.40(0.90-2.16)$ & 0.13 \\
\hline \multicolumn{5}{|l|}{ Smoking status } \\
\hline Never & Reference & & Reference & \\
\hline Former & $2.22(1.39-3.55)$ & 0.001 & $3.24(2.03-5.17)$ & $<0.001$ \\
\hline Current & $0.80(0.60-1.08)$ & 0.15 & $0.69(0.49-0.98)$ & 0.04 \\
\hline \multicolumn{5}{|l|}{ Household income } \\
\hline$<\$ 10,000$ & $1.04(0.58-1.87)$ & 0.89 & $0.96(0.59-1.57)$ & 0.87 \\
\hline$\$ 10,000$ to $\$ 25,000$ & $0.84(0.46-1.55)$ & 0.58 & $0.92(0.54-1.57)$ & 0.75 \\
\hline$>\$ 25,000$ to $<\$ 50,000$ & $0.83(0.43-1.57)$ & 0.56 & $0.95(0.50-1.80)$ & 0.88 \\
\hline$\geq \$ 50,000$ & Reference & & Reference & \\
\hline \multicolumn{5}{|l|}{ Marital status } \\
\hline Married & Reference & & Reference & \\
\hline Widowed & $1.15(0.77-1.72)$ & 0.48 & $0.83(0.59-1.18)$ & 0.30 \\
\hline Divorced/separated & $0.72(0.41-1.27)$ & 0.26 & $0.77(0.42-1.40)$ & 0.39 \\
\hline Never married & 1.07 (0.55-2.08) & 0.83 & $1.22(0.63-2.36)$ & 0.55 \\
\hline Cardiovascular disease & $0.75(0.57-0.95)$ & 0.04 & $0.91(0.67-1.23)$ & 0.52 \\
\hline Diabetes & $0.69(0.50-0.95)$ & 0.02 & $0.52(0.33-0.82)$ & 0.005 \\
\hline \multicolumn{5}{|l|}{ Physical Activity } \\
\hline Age & $0.98(0.94-1.03)$ & 0.51 & $0.95(0.90-1.00)$ & 0.07 \\
\hline Memphis site & Reference & & Reference & \\
\hline Pittsburgh site & $0.78(0.59-1.03)$ & 0.08 & $0.63(0.46-0.85)$ & 0.003 \\
\hline White race & Reference & & Reference & \\
\hline Black race & $0.69(0.51-0.94)$ & 0.02 & $0.46(0.33-0.64)$ & $<0.001$ \\
\hline \multicolumn{5}{|l|}{ Education } \\
\hline$<$ High school & Reference & & Reference & \\
\hline High school & $0.96(0.64-1.46)$ & 0.86 & $1.17(0.74-1.86)$ & 0.50 \\
\hline Postsecondary & $1.01(0.70-1.48)$ & 0.94 & $1.04(0.65-1.65)$ & 0.88 \\
\hline \multicolumn{5}{|l|}{ Smoking status } \\
\hline Never & Reference & & Reference & \\
\hline Former & $0.51(0.28-0.92)$ & 0.03 & $1.35(0.80-2.29)$ & 0.26 \\
\hline Current & $0.93(0.68-1.27)$ & 0.65 & $0.74(0.53-1.05)$ & 0.10 \\
\hline \multicolumn{5}{|l|}{ Household income } \\
\hline$<\$ 10,000$ & $1.18(0.60-2.33)$ & 0.64 & $1.16(0.69-1.97)$ & 0.58 \\
\hline$\$ 10,000$ to $\$ 25,000$ & $1.38(0.69-2.78)$ & 0.37 & $1.11(0.62-1.96)$ & 0.73 \\
\hline$>\$ 25,000$ to $<\$ 50,000$ & $1.28(0.62-2.67)$ & 0.51 & $1.29(0.67-2.51)$ & 0.45 \\
\hline$\geq \$ 50,000$ & Reference & & Reference & \\
\hline \multicolumn{5}{|l|}{ Marital status } \\
\hline Married & Reference & & Reference & \\
\hline Widowed & $0.72(0.45-1.15)$ & 0.17 & $1.04(0.73-1.50)$ & 0.82 \\
\hline Divorced/separated & $1.15(0.66-2.01)$ & 0.63 & $0.82(0.44-1.52)$ & 0.52 \\
\hline Never married & $0.62(0.28-1.37)$ & 0.24 & $1.00(0.48-2.11)$ & 0.99 \\
\hline Cardiovascular disease & $0.59(0.44-0.79)$ & $<0.001$ & $0.63(0.45-0.87)$ & 0.01 \\
\hline Diabetes & $0.82(0.59-1.15)$ & 0.25 & $0.92(0.61-1.41)$ & 0.71 \\
\hline
\end{tabular}


Table 5. Cont

\begin{tabular}{|c|c|c|c|c|}
\hline & \multicolumn{2}{|c|}{ Men } & \multicolumn{2}{|c|}{ Women } \\
\hline & OR $(95 \%$ CI) & $p$-Value & OR $(95 \% \mathrm{CI})$ & $p$-Value \\
\hline \multicolumn{5}{|l|}{ Fruits and Vegetables } \\
\hline Age & $1.01(0.97-1.06)$ & 0.56 & $1.05(1.00-1.09)$ & 0.04 \\
\hline Memphis site & Reference & & Reference & \\
\hline Pittsburgh site & $1.30(1.01-1.66)$ & 0.04 & $0.92(0.73-1.17)$ & 0.48 \\
\hline White race & Reference & & Reference & \\
\hline Black race & $0.55(0.42-0.72)$ & $<0.001$ & $0.87(0.68-1.10)$ & 0.25 \\
\hline \multicolumn{5}{|l|}{ Education } \\
\hline$<$ High school & Reference & & Reference & \\
\hline High school & $0.75(0.52-1.09)$ & 0.13 & $1.17(0.84-1.64)$ & 0.36 \\
\hline Postsecondary & $1.14(0.82-1.59)$ & 0.44 & $1.80(1.28-2.54)$ & 0.001 \\
\hline \multicolumn{5}{|l|}{ Smoking status } \\
\hline Never & Reference & & Reference & \\
\hline Former & $0.64(0.40-1.04)$ & 0.07 & $0.56(0.36-0.87)$ & 0.01 \\
\hline Current & $0.85(0.64-1.12)$ & 0.24 & $0.82(0.64-1.06)$ & 0.13 \\
\hline \multicolumn{5}{|l|}{ Household income } \\
\hline$<\$ 10,000$ & $0.75(0.43-1.32)$ & 0.32 & $1.04(0.72-1.51)$ & 0.83 \\
\hline$\$ 10,000$ to $\$ 25,000$ & $0.74(0.41-1.32)$ & 0.31 & $1.29(0.85-1.96)$ & 0.23 \\
\hline$>\$ 25,000$ to $<\$ 50,000$ & $0.90(0.49-1.67)$ & 0.74 & $2.15(1.26-3.66)$ & 0.005 \\
\hline$\geq \$ 50,000$ & Reference & & Reference & \\
\hline \multicolumn{5}{|l|}{ Marital status } \\
\hline Married & Reference & & Reference & \\
\hline Widowed & $0.88(0.60-1.30)$ & 0.52 & $0.85(0.64-1.13)$ & 0.25 \\
\hline Divorced/separated & $0.79(0.47-1.33)$ & 0.38 & $1.10(0.71-1.72)$ & 0.67 \\
\hline Never married & $1.26(0.67-2.36)$ & 0.48 & $0.76(0.43-1.36)$ & 0.36 \\
\hline Cardiovascular disease & $0.89(0.69-1.16)$ & 0.40 & $0.69(0.54-0.88)$ & 0.003 \\
\hline Diabetes & $1.06(0.79-1.42)$ & 0.69 & $1.22(0.89-1.66)$ & 0.22 \\
\hline \multicolumn{5}{|l|}{ Fiber } \\
\hline Age & $0.95(0.88-1.02)$ & 0.14 & $1.07(0.99-1.17)$ & 0.10 \\
\hline Memphis site & Reference & & Reference & \\
\hline Pittsburgh site & $0.95(0.62-1.45)$ & 0.81 & $0.51(0.30-0.85)$ & 0.009 \\
\hline White race & Reference & & Reference & \\
\hline Black race & $0.98(0.63-1.53)$ & 0.93 & $1.59(0.96-2.62)$ & 0.07 \\
\hline \multicolumn{5}{|l|}{ Education } \\
\hline$<$ High school & Reference & & Reference & \\
\hline High school & $0.99(0.51-1.93)$ & 0.98 & $0.77(0.38-1.55)$ & 0.46 \\
\hline Postsecondary & $1.52(0.45-2.70)$ & 0.16 & $1.20(0.62-2.33)$ & 0.59 \\
\hline \multicolumn{5}{|l|}{ Smoking status } \\
\hline Never & Reference & & Reference & \\
\hline Former & $0.57(0.25-1.30)$ & 0.18 & $0.57(0.20-1.64)$ & 0.30 \\
\hline Current & $0.62(0.39-0.98)$ & 0.04 & $0.72(0.41-1.27)$ & 0.25 \\
\hline \multicolumn{5}{|l|}{ Household income } \\
\hline$<\$ 10,000$ & $1.04(0.37-2.95)$ & 0.94 & $0.64(0.24-1.74)$ & 0.38 \\
\hline$\$ 10,000$ to $\$ 25,000$ & $0.96(0.50-1.82)$ & 0.89 & $0.49(0.21-1.18)$ & 0.11 \\
\hline$>\$ 25,000$ to $<\$ 50,000$ & $1.23(0.68-2.23)$ & 0.50 & $0.55(0.22-1.34)$ & 0.19 \\
\hline$\geq \$ 50,000$ & Reference & & Reference & \\
\hline \multicolumn{5}{|l|}{ Marital status } \\
\hline Married & Reference & & Reference & \\
\hline Widowed & $0.95(0.47-1.91)$ & 0.88 & $1.61(0.89-2.90)$ & 0.12 \\
\hline Divorced/separated & $1.55(0.72-3.33)$ & 0.36 & $1.12(0.43-2.95)$ & 0.82 \\
\hline Never married & $3.85(1.84-8.05)$ & $<0.001$ & $0.77(0.17-3.43)$ & 0.73 \\
\hline Cardiovascular disease & $0.83(0.54-1.29)$ & 0.41 & $1.26(0.76-2.10)$ & 0.37 \\
\hline Diabetes & $1.22(0.76-1.96)$ & 0.41 & $1.68(0.95-2.96)$ & 0.07 \\
\hline
\end{tabular}

OR represents the odds of meeting cancer prevention recommendations. Models adjusted for age, race, and study site. 


\section{Discussion and Implications}

This study adds to the body of evidence on adherence to cancer prevention guidelines by contributing information on populations for which there is limited evidence; older adults and black participants. Our results show that less than $1 \%$ of men and women adhered to all prevention guidelines assessed in our study, and overall adherence to prevention guidelines is particularly low among black participants and men. Conversely, guidelines for alcohol and red and processed meat consumption were followed by the majority of participants. This along with the variation in adherence to each cancer prevention guidelines suggests some guidelines may be easier to achieve than others.

In this cohort, adherence to fiber ( $9 \%$ and $6 \%$ ), was the lowest of the recommendations assessed. This is consistent with data from the 2009-2010 National Health and Nutrition Examination Survey that illustrated low fiber and whole grain intake among the general US population [31], as well as fiber being identified as a nutrient of public health concern by the 2015 Dietary Guidelines for Americans due to low intake [32]. The WCRF/AICR grades the evidence linking wholegrains and foods containing dietary fiber to colorectal cancers as 'strong' [7], suggesting the need for continual public health efforts to increase consumption, particularly given that colorectal cancer is the fourth most common cancer diagnosis in the United States and the second leading cause of cancer related deaths [17].

Adherence to the physical activity recommendation was also low in this cohort ( $26 \%$ and $18 \%)$. This may reflect the older age of the cohort as physical activity levels tend to decline with age [33]. It is also noteworthy that adherence was low despite a population that was well-functioning and physical activity was self-reported, which is prone to response bias [34]. Indeed, among adults aged 70 or older, only $6 \%$ to $10 \%$ meet recommendations for physical activity of $\geq 150$ minutes of MVPA/wk using accelerometry measured physical activity [35], which is lower than the cut point of $\geq 210$ minutes of MVPA/wk in our study. It is thus likely that adherence to physical activity guidelines in our population as well as the more general older population is even less than what we report.

Approximately one in four participants adhered to the guidelines for weight maintenance within the normal range throughout life, and upwards of $70 \%$ of men and $80 \%$ of women gained more than $5 \%$ of their body weight as they aged. This reflects the high prevalence of overweight and obesity in the United States; over 70\% among adults age 60 and older [36] and the predominant experience of weight gain with aging [37]. Body fatness is one of the strongest and most universal risk factor for cancer (as well as other chronic disease). Body fatness has been linked to twelve different types of cancer for which the evidence is rated as 'probable increased risk' for three cancers to 'convincing increased risk' for eight cancers which is the highest grade of evidence from the WCRF/AICR [7]. Obesity has been the focus of many public health efforts in the United States [38-40], however obesity rates remain high. More work is needed to develop effective strategies with a consideration of interventions that address preventable health behaviors among older populations.

Several factors-black race, former and current smoking, lower education and income, cardiovascular disease, and diabetes-were associated with lower likelihood of meeting individual prevention guidelines and/or having a lower composite score. Although former smoking was also associated with greater odds of weight maintenance, likely reflecting well-established relationships between lower weight and smoking. Our findings are consistent with well-known racial/ethnic and socioeconomic health disparities in health risk behaviors in the United States [41,42]. Cardiovascular disease and diabetes share many of the same modifiable risk factors as cancer including body fatness, physical activity, and some aspects of diet [43-46]. Thus, it is not surprising that participants with prevalent cardiovascular disease and diabetes were less likely to adhere to guidelines. Rather, this provides insight into specific populations who may be particularly at risk for cancer, and thus would benefit from targeted cancer prevention strategies.

Direct comparison with previous studies is limited by the challenges in assessing adherence to the WCRF/AICR recommendations. Clear cut points do not exist for all recommendations such as sedentary time, wholegrains, pulses, and non-starchy vegetables. Recommendations that include 'limit' or 'consume sparingly' are difficult to operationalize and compare across studies and the number of 
individual recommendations assessed in a given study is variable. That said, the overall finding of low engagement in cancer preventive behavior is consistent with previous studies across a variety of populations from different countries. Among men and women aged 50-71 [10], 12\% of men and $11 \%$ of women were in the lowest category of adherence. A study of women aged 50-79 [15] reported less than $1 \%$ of participants met all guidelines and similar to our findings reported lower adherence scores among women with less education, former or current smokers and black women. Jankovic et al. [16] reported adherence to recommendations for fiber, fruits, and vegetables and alcohol consumption that were in the same range as our results across the six older cohorts studied. Compared to studies of adherence in younger populations $[9,13,27,47]$, adherence to the body weight recommendation was consistently lower in our population, adherence to physical activity and fiber and alcohol recommendations were within the ranges previously reported and adherence to the recommendation for fruits and vegetables, red and processed meat were generally higher. Additional studies are needed to confirm whether older adults truly have a higher/lower adherence to specific recommendations than younger populations or whether differences reflect heterogeneity in study methods and cutpoints. Understanding meaningful differences in populations may help to focus prevention efforts.

A strength of our study is the recalled height and weight at ages 25 and 50. This enabled the assessment of maintenance of healthy body weight over time, which few prior studies have done. Another strength of our study is the population of older, black, and white adults, demographics that have been seldom captured in prior studies. However, since this study was confined to a specific age group, and data were collected in 1998-1999, the results may not be generalizable to contemporary older adults, particularly given the increase in body weight over the past two decades [48]. Participants were also recruited to be initially well functioning and thus selection bias may mean that the results do not reflect the larger population of 71-80 year olds regardless of the era of assessment. Diet, physical activity and alcohol were only assessed at a single time point, which may not capture variation. There are also limitations to our approach to operationalize the guidelines. We relied on previously published cut points for recommendations without well-defined criteria. As well, the WCRF/AIRC does not provide guidance on relative importance of recommendations, and the complexity of such an undertaking would be substantial. As a result, each individual component received an equal weight within the composite score even though the attributable risk of each factor may vary or only be associated with certain cancer types [7]. Additional work to facilitate comparable surveillance data on cancer preventive behaviors is needed.

In conclusion, our results suggest that few older adults adhere to guidelines for cancer prevention, thus illustrating the critical need for cancer prevention efforts in the rapidly aging population. Adherence was related to socioeconomic factors, race, and prevalent disease. Some guidelines such as fiber, physical activity and weight may be particularly difficult to meet. These findings may be helpful for informing cancer prevention strategies including identifying priority populations and behaviors to target.

Supplementary Materials: The following are available online at http:/www.mdpi.com/2072-6643/11/5/1008/s1, Table S1: Dietary intake (Mean, (SD)) in Health ABC of foods considered in the composite score of WCRF/AICR dietary recommendations.

Author Contributions: Conceptualization, R.A.M., Methodology, R.A.M., A.J.Y., and S.B.K., Formal Analysis, R.A.M. and A.J.Y., Writing—Original Draft Preparation, R.A.M., Writing—Review \& Editing, J.C., I.M., S.R., S.B.K., H.D.K., A.B.N., H.A., and T.B.H., Project Administration, H.A. and S.R., Funding Acquisition, T.B.H., S.B.K., and A.B.N.

Funding: Dr. Murphy's time was funded by the Canadian Cancer Society (grant \#704735) and the Michael Smith Foundation for Health Research (grant \#17644). This work was supported in part by the Intramural program of the National Institutes of Health, National Institute on Aging (NIA), and by NIA contracts N01-AG-6-2101; N01-AG-6-2103, N01-AG-6-2106, NIA grant R01-AG028050; and National Institute of Nursing Research Grant R01-NR012459.

Conflicts of Interest: The authors declare no conflicts of interest. 


\section{References}

1. Torre, L.A.; Bray, F.; Siegel, R.L.; Ferlay, J.; Lortet-Tieulent, J.; Jemal, A. Global cancer statistics, 2012. CA Cancer J. Clin. 2015, 65, 87-108. [CrossRef] [PubMed]

2. Bray, F.; Jemal, A.; Grey, N.; Ferlay, J.; Forman, D. Global cancer transitions according to the Human Development Index (2008-2030): A population-based study. Lancet Oncol. 2012, 13, 790-801. [CrossRef]

3. Arnold, M.; Pandeya, N.; Byrnes, G.; Renehan, P.A.G.; Stevens, G.A.; Ezzati, P.M.; Ferlay, J.; Miranda, J.J.; Romieu, I.; Dikshit, R.; et al. Global burden of cancer attributable to high body-mass index in 2012: A population-based study. Lancet Oncol. 2015, 16, 36-46. [CrossRef]

4. Vineis, P.; Wild, C.P. Global cancer patterns: Causes and prevention. Lancet 2014, 383, 549-557. [CrossRef]

5. World Cancer Research Fund/American Institute for Cancer Research. Food Nutrition, Physical Activity, and the Prevention of Cancer: A Global Perspective; AICR: Washington, DC, USA, 2007.

6. Kushi, L.H.; Doyle, C.; McCullough, M.; Rock, C.L.; Demark-Wahnefried, W.; Bandera, E.V.; Gapstur, S.; Patel, A.V.; Andrews, K.; Gansler, T.; American Cancer Society 2010 Nutrition and Physical Activity Guidelines Advisory Committee. American Cancer Society Guidelines on nutrition and physical activity for cancer prevention: Reducing the risk of cancer with healthy food choices and physical activity. CA Cancer J. Clin. 2012, 62, 30-67. [CrossRef] [PubMed]

7. World Cancer Research Fund/American Institute for Cancer Research. Continuous Update Project Expert Report 2018. Judging the Evidence. Available online: https://www.wcrf.org/dietandcancer (accessed on 1 October 2019).

8. Catsburg, C.; Miller, A.B.; Rohan, T.E. Adherence to cancer prevention guidelines and risk of breast cancer. Int. J. Cancer 2014, 135, 2444-2452. [CrossRef] [PubMed]

9. Cerhan, J.R.; Potter, J.D.; Gilmore, J.M.; Janney, C.A.; Kushi, L.H.; Lazovich, D.; Anderson, K.E.; Sellers, T.A.; Folsom, A.R. Adherence to the AICR cancer prevention recommendations and subsequent morbidity and mortality in the Iowa Women's Health Study cohort. Cancer Epidemiol. Biomark. Prev. 2004, 13, 1114-1120.

10. Kabat, G.C.; Matthews, C.E.; Kamensky, V.; Hollenbeck, A.R.; Rohan, T.E. Adherence to cancer prevention guidelines and cancer incidence, cancer mortality, and total mortality: A prospective cohort study. Am. J. Clin. Nutr. 2015, 101, 558-569. [CrossRef]

11. Kohler, L.N.; Hibler, E.A.; Harris, R.B.; Oren, E.; Roe, D.J.; Jurutka, P.W.; Jacobs, E.T. Greater Adherence to Cancer Prevention Guidelines Is Associated with Higher Circulating Concentrations of Vitamin D Metabolites in a Cross-Sectional Analysis of Pooled Participants from 2 Chemoprevention Trials. J. Nutr. 2017, 147, 421-429. [CrossRef] [PubMed]

12. Romaguera, D.; Vergnaud, A.C.; Peeters, P.H.; van Gils, C.H.; Chan, D.S.; Ferrari, P.; Romieu, I.; Jenab, M.; Slimani, N.; Clavel-Chapelon, F.; et al. Is concordance with World Cancer Research Fund/American Institute for Cancer Research guidelines for cancer prevention related to subsequent risk of cancer? Results from the EPIC study. Am. J. Clin. Nutr. 2012, 96, 150-163. [CrossRef]

13. Whelan, H.K.; Xu, J.Y.; Vaseghi, S.; Lo Siou, G.; McGregor, S.E.; Robson, P.J. Alberta's Tomorrow Project: Adherence to cancer prevention recommendations pertaining to diet, physical activity and body size. Public Health Nutr. 2017, 20, 1143-1153. [CrossRef]

14. McCullough, M.L.; Patel, A.V.; Kushi, L.H.; Patel, R.; Willett, W.C.; Doyle, C.; Thun, M.J.; Gapstur, S.M. Following cancer prevention guidelines reduces risk of cancer, cardiovascular disease, and all-cause mortality. Cancer Epidemiol. Biomark. Prev. 2011, 20, 1089-1097. [CrossRef]

15. Thomson, C.A.; McCullough, M.L.; Wertheim, B.C.; Chlebowski, R.T.; Martinez, M.E.; Stefanick, M.L.; Rohan, T.E.; Manson, J.E.; Tindle, H.A.; Ockene, J.; et al. Nutrition and physical activity cancer prevention guidelines, cancer risk, and mortality in the women's health initiative. Cancer Prev. Res. 2014, 7, 42-53. [CrossRef]

16. Jankovic, N.; Geelen, A.; Winkels, R.M.; Mwungura, B.; Fedirko, V.; Jenab, M.; Illner, A.K.; Brenner, H.; Ordonez-Mena, J.M.; Kiefte de Jong, J.C.; et al. Consortium on Health and Ageing: Network of Cohorts in Europe and the United States. Adherence to the WCRF/AICR Dietary Recommendations for Cancer Prevention and Risk of Cancer in Elderly from Europe and the United States: A Meta-Analysis within the CHANCES Project. Cancer Epidemiol. Biomark. Prev. 2017, 26, 136-144.

17. Cancer Facts E Figures 2018; American Cancer Society (ACS): Atlanta, GA, USA, 2018. 
18. Miller, S.M.; Bowen, D.J.; Lyle, J.; Clark, M.; Mohr, D.; Wardle, J.; Ceballos, R.; Emmons, K.; Gritz, E.; Marlow, L. Primary prevention, aging, and cancer: Overview and future perspectives. Cancer 2008, 113, 3484-3492. [CrossRef] [PubMed]

19. Byers, T. Targeting cancer prevention and screening practices for older adults. J. Am. Geriatr. Soc. 2009, 57 (Suppl. 2), S243-S245. [CrossRef]

20. Colditz, G.A.; Wolin, K.Y.; Gehlert, S. Applying what we know to accelerate cancer prevention. Sci. Transl. Med. 2012, 4, 127rv124. [CrossRef]

21. Luo, J.; Chlebowski, R.T.; Hendryx, M.; Rohan, T.; Wactawski-Wende, J.; Thomson, C.A.; Felix, A.S.; Chen, C.; Barrington, W.; Coday, M.; et al. Intentional Weight Loss and Endometrial Cancer Risk. J. Clin. Oncol. 2017, 35, 1189-1193. [CrossRef] [PubMed]

22. Visser, M.; Kritchevsky, S.B.; Goodpaster, B.H.; Newman, A.B.; Nevitt, M.; Stamm, E.; Harris, T.B. Leg muscle mass and composition in relation to lower extremity performance in men and women aged 70 to 79: The health, aging and body composition study. J. Am. Geriatr. Soc. 2002, 50, 897-904. [CrossRef]

23. Houston, D.K.; Nicklas, B.J.; Ding, J.; Harris, T.B.; Tylavsky, F.A.; Newman, A.B.; Lee, J.S.; Sahyoun, N.R.; Visser, M.; Kritchevsky, S.B.; et al. Dietary protein intake is associated with lean mass change in older, community-dwelling adults: The Health, Aging, and Body Composition (Health ABC) Study. Am. J. Clin. Nutr. 2008, 87, 150-155. [CrossRef]

24. Houston, D.K.; Ding, J.; Nicklas, B.J.; Harris, T.B.; Lee, J.S.; Nevitt, M.C.; Rubin, S.M.; Tylavsky, F.A.; Kritchevsky, S.B.; Health ABC Study. Overweight and obesity over the adult life course and incident mobility limitation in older adults: The health, aging and body composition study. Am. J. Epidemiol. 2009, 169, 927-936. [CrossRef] [PubMed]

25. Murphy, R.A.; Patel, K.V.; Kritchevsky, S.B.; Houston, D.K.; Newman, A.B.; Koster, A.; Simonsick, E.M.; Tylvasky, F.A.; Cawthon, P.M.; Harris, T.B.; et al. Weight change, body composition, and risk of mobility disability and mortality in older adults: A population-based cohort study. J. Am. Geriatr. Soc. 2014, 62, 1476-1483. [CrossRef]

26. Taylor, H.L.; Jacobs, D.R., Jr.; Schucker, B.; Knudsen, J.; Leon, A.S.; Debacker, G. A questionnaire for the assessment of leisure time physical activities. J. Chronic Dis. 1978, 31, 741-755. [CrossRef]

27. Inoue-Choi, M.; Lazovich, D.; Prizment, A.E.; Robien, K. Adherence to the World Cancer Research Fund/American Institute for Cancer Research recommendations for cancer prevention is associated with better health-related quality of life among elderly female cancer survivors. J. Clin. Oncol. 2013, 31, 1758-1766. [CrossRef]

28. Kabat, G.C.; Kim, M.; Hunt, J.R.; Chlebowski, R.T.; Rohan, T.E. Body mass index and waist circumference in relation to lung cancer risk in the Women's Health Initiative. Am. J. Epidemiol. 2008, 168, 158-169. [CrossRef] [PubMed]

29. Giovannucci, E.; Rimm, E.B.; Liu, Y.; Leitzmann, M.; Wu, K.; Stampfer, M.J.; Willett, W.C. Body mass index and risk of prostate cancer in U.S. health professionals. J. Natl. Cancer Inst. 2003, 95, 1240-1244. [CrossRef]

30. Whittemore, A.S.; Kolonel, L.N.; Wu, A.H.; John, E.M.; Gallagher, R.P.; Howe, G.R.; Burch, J.D.; Hankin, J.; Dreon, D.M.; West, D.W.; et al. Prostate cancer in relation to diet, physical activity, and body size in blacks, whites, and Asians in the United States and Canada. J. Natl. Cancer Inst. 1995, 87, 652-661. [CrossRef]

31. Reicks, M.; Jonnalagadda, S.; Albertson, A.M.; Joshi, N. Total dietary fiber intakes in the US population are related to whole grain consumption: Results from the National Health and Nutrition Examination Survey 2009 to 2010. Nutr. Res. 2014, 34, 226-234. [CrossRef] [PubMed]

32. U.S. Department of Health and Human Services; U.S. Department of Agriculture. 2015-2020 Dietary Guidelines for Americans. 8th Edition. December 2015. Available online: https://health.gov/ dietaryguidelines/2015/guidelines/ (accessed on 15 October 2018).

33. Colley, R.C.; Garriguet, D.; Janssen, I.; Craig, C.L.; Clarke, J.; Tremblay, M.S. Physical activity of Canadian adults: Accelerometer results from the 2007 to 2009 Canadian Health Measures Survey. Health Rep. 2011, 22, 7-14. [PubMed]

34. Dyrstad, S.M.; Hansen, B.H.; Holme, I.M.; Anderssen, S.A. Comparison of self-reported versus accelerometer-measured physical activity. Med. Sci. Sports Exerc. 2014, 46, 99-106. [CrossRef]

35. Tucker, J.M.; Welk, G.J.; Beyler, N.K. Physical activity in U.S.: Adults compliance with the Physical Activity Guidelines for Americans. Am. J. Prev. Med. 2011, 40, 454-461. [CrossRef] [PubMed] 
36. Ogden, C.L.; Carroll, M.D.; Flegal, K.M. Prevalence of obesity in the United States. JAMA 2014, 312, $189-190$. [CrossRef] [PubMed]

37. Williamson, D.F.; Kahn, H.S.; Remington, P.L.; Anda, R.F. The 10-year incidence of overweight and major weight gain in US adults. Arch. Intern. Med. 1990, 150, 665-672. [CrossRef]

38. Food and Nutrition Service; USDA. Special Supplemental Nutrition Program for Women, Infants and Children (WIC); U.S. Department of Agriculture (USDA) Food and Nutrition Service. Available online: https: //www.fns.usda.gov/wic/women-infants-and-children (accessed on 25 September 2018).

39. Institute of Medicine. Accelerating Progress in Obesity Prevention: Solving the Weight of the Nation; National Academies Press: Washington, DC, USA, 2012; Available online: http://iom.edu/reports/2012/acceleratingprogress-in-obesity-prevention.aspx (accessed on 27 April 2018).

40. Khan, L.K.; Sobush, K.; Keener, D.; Goodman, K.; Lowry, A.; Kakietek, J.; Zaro, S. Recommended community strategies and measurements to prevent obesity in the United States. MMWR Recomm. Rep. 2009, 58, 1-26.

41. Gordon-Larsen, P.; Nelson, M.C.; Page, P.; Popkin, B.M. Inequality in the built environment underlies key health disparities in physical activity and obesity. Pediatrics 2006, 117, 417-424. [CrossRef] [PubMed]

42. Wang, Y.; Beydoun, M.A. The obesity epidemic in the United States-Gender, age, socioeconomic, racial/ethnic, and geographic characteristics: A systematic review and meta-regression analysis. Epidemiol. Rev. 2007, 29, 6-28. [CrossRef]

43. Lindstrom, J.; Peltonen, M.; Eriksson, J.G.; Louheranta, A.; Fogelholm, M.; Uusitupa, M.; Tuomilehto, J. High-fibre, low-fat diet predicts long-term weight loss and decreased type 2 diabetes risk: The Finnish Diabetes Prevention Study. Diabetologia 2006, 49, 912-920. [CrossRef] [PubMed]

44. Klein, S.; Sheard, N.F.; Pi-Sunyer, X.; Daly, A.; Wylie-Rosett, J.; Kulkarni, K.; Clark, N.G.; American Diabetes Association; North American Association for the Study of Obesity; American Society for Clinical Nutrition. Weight management through lifestyle modification for the prevention and management of type 2 diabetes: Rationale and strategies: A statement of the American Diabetes Association, the North American Association for the Study of Obesity, and the American Society for Clinical Nutrition. Diabetes Care 2004, 27, 2067-2073. [PubMed]

45. Gill, J.M.; Cooper, A.R. Physical activity and prevention of type 2 diabetes mellitus. Sports Med. 2008, 38, 807-824. [CrossRef]

46. Thompson, P.D.; Buchner, D.; Pina, I.L.; Balady, G.J.; Williams, M.A.; Marcus, B.H.; Berra, K.; Blair, S.N.; Costa, F.; Franklin, B.; et al. American Heart Association Council on Clinical Cardiology Subcommittee on Exercise, Rehabilitation, and Prevention, American Heart Association Council on Nutrition Physical Activity and Metabolism Subcommittee on Physical Activity. Circulation 2003, 107, 3109-3116. [CrossRef]

47. Hastert, T.A.; Beresford, S.A.; Patterson, R.E.; Kristal, A.R.; White, E. Adherence to WCRF/AICR cancer prevention recommendations and risk of postmenopausal breast cancer. Cancer Epidemiol. Biomark. Prev. 2013, 22, 1498-1508. [CrossRef] [PubMed]

48. NCD Risk Factor Collaboration. Trends in adult body-mass index in 200 countries from 1975 to 2014: A pooled analysis of 1698 population-based measurement studies with 19.2 million participants. Lancet 2016, 387, 1377-1396. [CrossRef]

(C) 2019 by the authors. Licensee MDPI, Basel, Switzerland. This article is an open access article distributed under the terms and conditions of the Creative Commons Attribution (CC BY) license (http://creativecommons.org/licenses/by/4.0/). 